\title{
A Case Study of Knowledge Exchange in a Hierarchical Mechanism
}

\author{
Indria Handoko* \\ Universitas Prasetiya Mulya, Jakarta, Indonesia
}

\begin{abstract}
This research investigates knowledge exchange in an organization applying hierarchical mechanisms, and the influence of social interactions on knowledge flow across different levels of analysis. The research uses a qualitative case study method of an Indonesian automotive component-making company, applying semi-structured interviews, observations, and focus groups at interorganizational, internal company, and shopfloor levels. The research main finding is that in an organization applying hierarchical mechanisms, social interactions that exist at one level are able to influence interactions at other levels, and that the interactions can both facilitate and inhibit knowledge exchange across levels and boundaries. The application of any formal mechanism at interorganizational level needs to consider both the dynamics operating at social level and the potentially disparate and contradictory effects it may have if its aim is to promote knowledge flow across levels. The application of in-depth exploratory case study research contributes to the conceptualization of relationships between knowledge exchange, social interactions, and governance mechanism.
\end{abstract}

\begin{abstract}
Abstrak: Studi ini menelitipertukaran pengetabuan dalam suatu organisasi yang menerapkan mekanisme birarkis, dan tentang pengaruh interaksi sosial pada aliran pengetahuan lintas tingkat analisis yang berbeda-beda. Metoda riset yang digunakan adalah studi kasus kualitatif pada perusahaan pembuat komponen otomotif di Indonesia, dengan menggunakan wawancara semi-strukturan, observasi, dan kelompok fokus pada tingkat interorganisasional, perusabaan internal, dan 'shopfloor.' Temuan utama riset ini adalab babwa dalam suatu perusabaan yang menerapkan mekanisme birarkis, interaksi sosial pada satu tingkat dapat mempengarubi interaksi pada tingkat lainnya, dan interaksi tersebut dapat baik memfasilitasi maupun menghambat pertukaran pengetabuan lintas tingkat dan batas. Penerapan mekanisme formal pada tingkat interorganisasional perlu mempertimbangkan baik. dinamika pengoperasian pada tingkat sosial maupun dampak. yang secara potensial memisabkan dan kontradiktif, apabila perusahaan ingin memfasilitasi terjadinya aliran pengetabuan lintas tingkat. Penerapan riset studi kasus eksploratori secara mendalam ini berkontribusi pada pengembangan konseptualisasi relasi antara pertukaran pengetahuan, interaksi sosial, dan mekanisme tata kelola.
\end{abstract}

Keywords: knowledge exchange; manufacturing industry; qualitative research; social interaction

JEL classification: L6, M1

* Corresponding author's e-mail: indria@pmbs.ac.id 


\section{Introduction}

It is widely believed that a company's sustainability and success are, at least to a certain degree, dependent upon how it is able to acquire and utilise knowledge derived from the network in which it resides (e.g. Lambert et al. 1998, Barratt 2004, Squire et al. 2009). Repeated and continuing exchange relationships between the network members potentially promote the creation of knowledge (e.g. Inkpen and Tsang 2005). This article addresses the idea of knowledge exchange as a socially complex phenomenon, consisting of factors which involve individuals and groups who have certain mindsets and interests (Brown and Duguid 2001, Tsoukas and Vladimirou 2001, Orlikowski 2002). This suggests that investment in relations-specific assets enables companies to utilise network resources through knowledge exchange, by which company performance on the part of both parties can be enhanced (e.g. Gulati et al. 2000, Krause et al. 2007).

This article underlines that companies engaged in a supply chain context are required to be able to synchronies internal activities with the supply chain dynamics, for example to make improvements to their production process (cf. Turnbull et al. 1992, Mentzer et al. 2001, Barratt 2004). Having said this, supply chains are governed by certain formal or hierarchical mechanisms, which can inhibit the flow of knowledge from one level to another level. Buyers, for example, have been known to impose their requirements in the form of contracts upon dependent suppliers to bear inventory costs, by which discussions of finding better mechanism might be difficult to be generated. The application of formal governance therefore potentially limits the explanation of the social and relational characteristics of exchange processes, includ- ing knowledge exchange (e.g. Turnbull et al. 1992, Bresnen 1996). How knowledge exchange occurs in such a hierarchical mechanism has hitherto been rarely discussed in the existing literature.

Moreover, there is a weakness in existing literature about knowledge exchange in not differentiating between internal levels, and focusing mainly on discussion at interorganizational level. As a result, many things remain unknown, for example, how a hierarchical mechanism at inter-organizational level influences social dynamics at shopfloor level and affects the flow of knowledge across levels. In this respect, the existing literature focuses on the perspective of buyers, and rarely that of suppliers (e.g. Cooper et al. 1997, Mentzer et al. 2001). In supply chains, buyers tend to employ formal mechanisms in their dealings with suppliers, which will orchestrate supply chain activities and direct each process in order that their requirements are met. Investigating supplier's perspective is thus essential to obtain a fuller understanding of, for instance, how supplier moderates any dependency on buyer by exercising strategic choices (Child 1972).

This article aims to investigate how knowledge exchange occurs in a company that is engaged in a hierarchical mechanism (namely formal governance), and how social interactions across different levels of analysis influence knowledge exchange. This study takes as its focus an investigation into the phenomena of knowledge exchange in the production activities of one manufacturing company which exist in a supply chain. This context has been chosen because it represents how formal governance, which dominates traditional supply chain mechanism (e.g. Turnbull et al. 1992, Takeishi 2001), influences social interactions as the characteristic of knowledge exchange. A qualitative case 
study approach is applied within the boundary of a supply chain in the Indonesian automotive component industry, as a good example of an industry that is engaged in a strictly-controlled mechanism. Indonesia has been chosen as an exemplar of an emerging country in Asia where manufacturing industry plays an important role in the national economy. Exploring interactions in this context would allow the research to capture any specific local cultural influences on patterns of knowledge exchange. This helps to gain a better understanding about how social interactions and formal mechanism at inter-organizational level together influence knowledge exchange.

\section{Literature Review}

\section{The Hierarchical Mechanism of Supply Chain}

Supply chain is perceived as an institutional form of coordinating economic exchange relations among actors which exist under a specific corporate identity, and a means of institutionalizing a recurring exchange relationship (see Ebers 1997, Inkpen and Tsang 2005). It involves multiple companies and coordinated business activities across functions, and incorporates the flow of products, services, and information (e.g. Mentzer et al. 2001, Ketchen and Hult 2007). Every function within a supply chain is considered a key process; thus each company needs the capability to manage its internal activities and align them with their supply chain processes and external relationships (e.g. Turnbull et al. 1992, Mentzer et al. 2001, Takeishi 2001, Barratt 2004).

Some authors (such as Turnbull et al. 1992, Takeishi 2001) argue that by effectively managing the buyer-supplier relationship, buyers can achieve a competitive advantage, for example, by gaining cost reductions in manufacturing operations through establishing effective purchasing mechanisms with suppliers. Accordingly, buyers tend to employ specific mechanisms in their dealings with suppliers which will orchestrate supply chain activities and direct each process in order that their requirements are met (e.g. Cooper et al. 1997, Mentzer et al. 2001). Applying this type of control mechanism (namely formal governance) suggests a top-down approach on the part of buyers. Formal governance is usually applied at the outset of cooperation between supplier and buyer. Its purpose is to direct inter-organizational exchange (Williamson 1985, Ring and Ven 1992, Poppo and Zenger 2002) by referring to a set of prescriptive statements which guide organizational behavior by specifying the roles and obligations of each party appropriate to the pursuance of specific goals (Cannon et al. 2000 in Carey and Lawson 2011, Tsoukas and Vladimirou 2001).

At the same time, Macneil (1985) argues that buyer-supplier relationships depend most importantly upon trust and reciprocity norms. Gulati and Singh (1998) put in that the existence of inter-organizational trust promotes interdependence and task coordination between companies, enabling them to work closely together with less formal controls. This reflects the nature of the contract at work in social networks and suggests a different form of governance, namely relational governance, which is defined by its use of flexibility, information-sharing, and the norms of solidarity present in a relationship (Carey and Lawson 2011, Poppo and Zenger 2002, Macneil 1985). It allows buyer and supplier to engage in exchange processes ( $\mathrm{Uz}_{\mathrm{z}} 1$ 1997), interacting within socially structured mechanisms (Gulati and Gargiulo 1999). 
Here, both parties engage in a set of informal norms which affect behavior in a way which preserves reputation and aims to establish a long-term relationship (Carey and Lawson 2011). In this way, social control (see Larson 1992) or self-enforcing safeguards such as relational or goodwill trust and reputation (Smitka 1991, Dyer 1996) can be enhanced, suggesting an alternative control mechanism.

The existing literature suggests that a company's choice of governance arrangements is influenced by several factors. For example, Baker (1990) proposes that it may depend upon a firm's embeddedness in particular social networks. Carey and Lawson (2011) suggest that the effectiveness of a governance structure depends on the degree of uncertainty at work, for example in supply market and product demand. Their study also indicates that both formal and relational governance complement rather than substitute each other. In brief, these studies suggest that different interests or goals exist between companies, underpinning governance arrangements.

When supplier and buyer work together with the aim of fulfilling the needs of each party and achieving long-term benefits for both, this is an indication of a developing interdependency (Bradach and Eccles 1989, Provan and Gassenheimer 1994). In a complex product industry such as the automotive industry, a high degree of interdependency is needed between supplier and buyer to enable fast decision-making and flexibility of product development (Turnbull et al. 1992; Takeishi 2001; Krause et al. 2007). Likewise, when supplier and buyer engage in a collaborative activity, the need for coordination increases, a further indication of increased interdependence (Provan and Gassenheimer 1994, Krause et al. 2007).
An interdependent relationship is however not without its areas of difficulty. Ambiguities may arise in the perceived value derived from a collaboration (e.g. Barratt 2004), perhaps in the handling of the cost of investment compared to the potential profit to be gained. Powerful buyers have been known to impose their requirements on dependent suppliers, forcing them to bear inventory costs (Turnbull et al. 1992). Understandably, decisions taken by buyers are largely motivated by a desire to obtain reductions in cost and efficient production processes. These decisions, mainly focusing on subjective interpretation and choice (Bresnen 1996; Krause et al. 2007) give rise to concerns about the structure and dynamics of the relationship. In other words, even when the relationship appears to be collaborative, a control mechanism appears to exist, which is explicit and applied by buyers to suppliers (Turnbull et al. 1992; Bresnen 1996). Thus, regardless of the benefits of interdependence, it may be difficult to accommodate the interests of each party. This issue however has hitherto hardly elaborated in the supply chain literature, including its effect on knowledge flow across supply chain levels of interaction.

\section{An Overview of Knowledge}

Tsoukas (2005) points out that organizations have to deal with changes in organizational practice and the capacity of individuals at a social level in a complex business environment. This suggests that knowledge flow across organizations has proved challenging, as the situated character of knowledge makes it both 'sticky' and 'leaky' (Hippel 1994, Szulanski 1996, Brown and Duguid 2001). The notion of internal stickiness is understood as a difficulty in knowledge transfer within an organization as a reflection of the cost of knowledge transfer. In contrast, 
the notion of 'leakiness' addresses the loss of knowledge as a result of porous boundaries between companies. This has a potentially negative impact upon a company's competitive advantage, which is dependent on the company's ability to prevent knowledge leaking to competitors (Liebeskind 1996).

The issues of knowledge stickiness and leakiness are of importance in understanding knowledge flow within supply chains. For instance, a buyer's high degree of dependency on a supplier providing important raw materials influences an interest in acquiring the supplier's knowledge in order to secure the materials supply, encouraging the buyer either to apply more relational contracting to ensure knowledge flow (cf. Provan and Gassenheimer 1994). This suggests that governance can play an important part in managing knowledge spillover (Nooteboom 2000). The main concern is that stickiness can be a problem in supply chains as formal governance may inhibit knowledge flow, and at the same time leakiness can be a problem if relational governance allows too much knowledge flow outside an organization. However, the existing literature (e.g. Krause et al. 2007, Aggarwal et al. 2011, Whipple et al. 2015) hardly discusses how these problems can be moderated by internal differentiation across levels of interaction, whether stickiness or leakiness may increase or decrease as a result. This constitutes a significant gap in the understanding of knowledge exchange in an organizational context with a strictly-controlled mechanism.

In the organizational context, Tsoukas and Vladimirou (2001) define knowledge as the 'individual capability to draw distinctions, within a domain of action, based on an appreciation of context or theory, or both' ( $p$. 973). This can enable individuals to act in new ways (Coleman 1988), concerns the per- sonal character of knowledge (Polanyi 1958), and at the same time addresses the collective character of knowledge (Teece et al. 1994, Tsoukas and Vladimirou 2001). Tsoukas and Vladimirou (2001) define organizational knowledge thus: 'the capability members of an organization have developed to draw distinctions in the process of carrying out their work, in particular concrete contexts, by enacting sets of generalizations (propositional statements) whose application depends on historical evolved collective understandings and experiences' (p. 983). They argue that the more propositional statements and collective understandings are instrumentalized, and the more new experiences are reflectively processed, and that the more the organizational members dwell in all of them, the more able they become to concentrate on new experiences (p. 983). This implies that a company needs to promote ongoing interaction among its organizational members, so that rules can be effectively institutionalized. Regarding this, Tsoukas (2005) proposes two types of organizational knowledge: propositional knowledge at institutional level and narrative knowledge at the level of practice.

Propositional knowledge is derived from an assumption that the phenomenon is 'patterned, composed of objectively available elements that can be represented via an abbreviated formula' (p. 71). In such an ordered mechanism, routines and patterns are institutionalized, delimiting modes of interaction, and the connections between individuals within an organization become determined by roles. In supplier-buyer relationships this is embodied in formal governance which represents coordinated mechanisms guided by the enduring principles of cooperation (Kogut 2000), such as design specifications and procedures. 
However, the application of governance cannot be done merely through the use of rules; the organized contexts are also open systems in a constant state of change. Constructing refined rules is thus needed; appropriate to the contexts, customs, and practices (Brown and Duguid 1991, Tsoukas 2005). In this account, rules are supplemented by narrative knowledge, which according to Tsoukas (2005) is contingent with the action of individuals, facilitating social interaction and preserving a community's collective memory, thus enhancing shared identity. This indicates a company's ability to facilitate ongoing interaction in order to promote exchange processes. Narrative knowledge thus closely relates to how knowledge is perceived as practice. This perspective regards knowledge as a social construct embedded in practice and the context of its application (e.g. Brown and Duguid 2001). Practice is defined by Cook and Brown (1999) as: 'coordinated activities of individuals and groups in doing their 'real work' as it is informed by a particular organizational or group context' (p. 387). This perspective suggests that besides governed by formal governances in the form of propositional knowledge at inter-organizational level, supply chains also comprise of social interactions in the form of narrative knowledge that occurs at social or individual level.

\section{Summary -The Research Question}

Addressing the problem of knowledge exchange in a hierarchical mechanism involves two groups of knowledge: propositional and narrative. In terms of propositional knowledge, potential problems exist in terms of the barriers associated with governance mechanisms, which potentially influence the occurrence of knowledge stickiness/leakiness which can affect knowledge flow in supply chains. Such barriers when emerging in the arena of external relations can potentially inhibit close interaction aimed at facilitating knowledge exchange at individual level. However, the existing literature does not consider how these problems can be moderated by internal differentiation across levels of interaction, where stickiness and leakiness may be heightened or reduces as a result.

Moreover, the existing studies mostly focus on discussion of governance arrangements at inter-organizational level, with minimal elaboration of interaction at internal-hierarchical levels. Similarly, the theoretical background of knowledge exchange leads us to identify a literature gap regarding the problems of knowledge stickiness and leakiness. The existing literature mainly relates the problems of governance arrangements and does not explain how these problems can be moderated by internal differentiation across levels of interaction. Emerging from these main concerns the research question is formulated:

"How does knowledge exchange occur in an organization that is governed with a hierarchical mechanism, and how does social interaction influence knowledge exchange across different levels?"

\section{Method}

The methodological approach needs to be one which can help the researcher gain an in-depth understanding of social interactions at different levels of analysis, and which relates to the occurrence of knowledge exchange influenced by hierarchical mechanisms. With this purpose in mind, case study research has been chosen as the main research methodology, which is defined by Creswell (2007) as: 'a qualitative approach in which the investigator explores a bounded system (a case) or multiple bounded systems (cases) over time, through detailed, in-depth data 
collection involving multiple sources of information, and reports a case description and casebased themes' (p. 73, italics as original). While quantitative research is important to provide statistically generalizable patters, a qualitative case study research offers reports from key participants that can describe complex processes that exist within organizations. Case study research thus provides a method that captures in a more holistic way the complexities of interaction within particular settings (Bryman 2008).

The notion of the case study as description closely relates to an interpretivist epistemological position, which builds case study research on the assumption that human understanding and action are based on an interpretation of specific organizational events (Isabella 1990). As the examination of knowledge exchange deals with the phenomena of social interaction, and it is typically a subtle process, capturing the participants' subjective interpretation of this process is necessary to adequately reveal the nature of events taking place.

The data collection in case study research is typically extensive, drawing on multiple sources of information within a bounded system (Creswell 2007). In this study, the boundary was set around particular production activities in one automotive manufacturing company in Indonesia: COMPO. ${ }^{1}$ COMPO has been chosen to represent a component-making supplier that manufactures automotive components (mass production). The component maker works primarily according to rigid hierarchical governance, manufactures components according to buyer's standard design, competes with many players, and strives to achieve cost reduction targets to sustain in business. This type of company provides a picture of how the application of formal governance influences how people exchange knowledge with each other.

The sources of data are primarily acquired from qualitative interviewing (semistructured interviews) (see Appendix 1 for the interview guideline), supported by observations and focus groups. Interviews ranged across three levels within the company: inter-organizational level (comprises senior managers who were involved in establishing supply chain formal contracts), internal company level (comprises middle managers charged with the implementation of the contracts), and shopfloor level (comprises foreman and operator positions involved in production). In total, 34 participants were interviewed to represent the three levels: 5 people at inter-organizational level ( 2 buyers and 3 suppliers), 14 people from internal company level, and 15 people from shopfloor level. Interviews focused on processes of knowledge exchange, ranging between 45-120 minutes and were recorded and transcribed. Repeat visits and interviews were used where appropriate and the companies were visited a number of times over the course of a year.

Observation is used to validate qualitative interviewing, as it offers a greater extent of obtaining findings in more natural ways (Mason 2002). It is one means of affirming interview findings. The researcher chose to act as an overt observer, which can result either in positive or negative effects. On the positive side, the researcher is 'allowed' by the people being observed to behave 'strangely or variably' during observation (Gill and Johnson 2006), for example by

${ }^{1}$ All company names in this paper are treated anonymously due to confidentiality agreements between the author and the companies. 
taking pictures and notes. On the negative side, participants may not behave naturally as their awareness of being observed can distort the findings. Observations were conducted on arrival at each company, and included events, people's behavior, the office layout, and company artefacts. Observations were particularly assiduous during, among others, formal meetings, factory tours, and lunchtime in the factory canteen.

Focus group is purposed to explore specific issues arising from the interview (Bryman 2008) and to confirm the interview data. In this activity, the participants are aware of the perspective of others in the group and may reconsider their own interpretation as a result (Ambrosini and Bowman 2001). Different arguments may thus emerge from the same participant in interview and in focus group. However, these differences may help the researcher to sharpen their understanding of (for example) how participants interpret a particular issue, which may also indicate the culture and subcultures of a company. Two focus groups were held: one made up of foremen or shopfloor leaders, and one composed of operators. Each group comprised five participants. Each focus group discussion lasted for around 60-90 minutes, designed to be held in a relaxed situation; snacks and drinks were served, and sometimes jokes were told. The discussion began with the researcher asking each participant their position, responsibility, and period of tenure in the company. Then followed an introductory question about the general perception of interaction between either internal or external parties. The main questions then addressed detailed issues of interaction, such as routine communication during and after work hours and when solving problems, the importance or results of the interaction, and the barriers each participant faced in communication.

In addition, in order to gain additional information about the company culture, the researcher also referred to the company's artifacts as a source of data. These can constitute a highly heterogonous set of data sources, being either personal (such as letters and photographs) or official documents (company profile, production flow charts, or pertaining to the organizational structure) (Bryman 2008). In interpreting these documents, the researcher also paid attention to the social and historical context within which they had been produced (cf. Bryman 2008).

In brief, the triangulation of data sources will have enhanced the quality of this research (as one method supplements the others), allowing the researcher to gain more accurate information and improve the robustness of theory being generated (cf. Martin and Eisenhardt 2010). The activities of data collection were supported by structured guidance based upon the qualitative research framework supplied by Miles and Huberman (1994) to reduce the possibility of missed identification of facts, specific details, and other pieces of information found in the field. The data is mostly treated as narrative data.

Data analysis involved an iterative process of data collection and emerging case interpretation involving all three authors (Miles and Huberman 1994). NVivo software was used and a coding frame was developed that combined open and axial coding methods (Corbin and Strauss 1990). This allowed the data to be coded according to the concepts of interest, while also allowing any emerging concepts of importance to the study to be 
captured. This structural approach (i.e. data codification) was enacted in a process of employing categorical aggregation, trying to encapsulate both pre-establishing codes and the search for emerging codes processes. In a less-structural approach, the analysis deals with direct interpretation while interviewing or observing. So, when a new concept emerges either during data collection or data analysis, the structural approach helps to build (or reinforce) connections between elements before formulating final patterns.

\section{The Case Study: COMPO}

The company profile of the company studied in this research is outlined on Table 1.

Knowledge exchange identified in this company occurred at three levels: inter-orga- nizational, internal company, and shopfloor, as described below.

\section{Knowledge exchange at inter-organizational level}

Knowledge flow at inter-organizational level can be identified in how COMPO dealt with the supply chain activities which addressed both routine and non-routine tasks. In terms of the former, knowledge exchange occurred mostly during activities concerning product supply issues, for instance product delivery or product reject rate. The main customer, CUSTO, visited COMPO every week, aiming particularly at helping COMPO expedite technical problem-solving and discussing possible improvements to the line with the production team. One COMPO production manager described that knowledge exchange during the routine visits normally re-

Table 1. Company Profile

\begin{tabular}{|c|c|}
\hline Category & COMPO \\
\hline Year of establishment & 1976 \\
\hline Product & $\begin{array}{l}\text { Manufactured components for automobiles and motorcycles. In 2012, its } \\
\text { products formed around a } 43 \text { per cent share of Indonesia's motorcycle } \\
\text { market, and around } 65 \text { per cent of the Indonesian automobile market. }\end{array}$ \\
\hline Number of employees & 2400 people \\
\hline Sales revenue (2012) & USD260 million \\
\hline Customer & $\begin{array}{l}\text { More than } 20 \text { customers, around } 85 \% \text { were OEMs (original equipment } \\
\text { manufacturers) and } 15 \% \text { were replacement parts market customers. Seventy } \\
\text { per cent of its OEM market was fulfilled by CUSTO, on which COMPO } \\
\text { was thus highly dependent. COMPO was always under pressure from } \\
\text { CUSTO to provide the most competitive price. }\end{array}$ \\
\hline Supplier & $\begin{array}{l}\text { There were more than } 100 \text { suppliers from raw materials, components, } \\
\text { equipments, to machine-making suppliers. }\end{array}$ \\
\hline $\begin{array}{l}\text { The structure of } \\
\text { Production Division }\end{array}$ & $\begin{array}{l}\text { A plant director managed } 8 \text { managers, each in charge of a department. Each } \\
\text { department had } 9 \text { production sections, each led by a supervisor. Each } \\
\text { section consisted of up to } 3 \text { production lines. Between } 3 \text { to } 10 \text { foremen } \\
\text { headed up each production line and each foreman supervised around } 20 \text { to } \\
30 \text { operators. Foremen and operators are taken here to represent the } \\
\text { shopfloor level. }\end{array}$ \\
\hline
\end{tabular}


sulted in snapshot problem-solving or improvements, which suggests that continuous improvements could be generated through routine customer visits. Whereas non-routine tasks comprised joint projects between $\mathrm{COMPO}$ and its customers, such as projects to increase labor productivity or to new product development.

In circumstances where an agreement was required between COMPO and customers, the marketing division usually mediated the negotiation processes. The marketing manager shared an example:

Frequent knowledge exchange happens with customers... We said to them, "There's a problem..." and [they answered], "Oh, this is the cause; you're wrong...". But it is because they used upper tolerance... We [then] negotiated [a solution]: "Okay, we offer you the use of bottom tolerance, so if we surpass it a bit, it's still allowed..." We tried to understand their situation... We asked [them], "If [we adjust it] like this, what's your problem?" "Oh... it's like this..." We discussed... "What can I do for you?"... So we learnt from them, and they learnt from us.

The indication is that the manager attempted to build shared understanding around certain task-specific knowledge to achieve an agreement with the buyer's staff about work performance. At the same time, he tried to build a shared understanding with COMPO's internal team, attempting to understand the production team's perspective while trying to address the customer's need, as he explained:

So what the customer's need is and what is actually going on in internally, we bridge [them]... We (i.e. marketing) bring the customer's need to production [division] - "This is what they want" because we've already promised the customer that "We will make like this...". When we (i.e. marketing and production) investigate, we find the root cause, so we discuss, "It should be like this... Condition A will cause an 'out-of-spec' for the customer, so [it] has to be covered by blah-blahblah...". This blab-blab-blah, we have to deliver to production... They (i.e. the production) ask why, and we tell them the reasons... and then we investigate why this happened.

The manager attempted to understand the production team's perspective, while at the same time trying to address the customer's need. This adoption of a mediation role indicates he was dealing with a two-way process to find the best solution for both parties. Here, the mediation role was applied to ensure that internal activities were aligned with the supply chain mechanism.

At the same time, communication between COMPO and its suppliers was mediated by the procurement division. In routine visits to COMPO shopfloor, suppliers were put in direct contact with the relevant divisions. Over time, as communication between the supplier and COMPO developed along more informal lines, a greater degree of familiarity arose. This situation, was exemplified by the supplier:

We visit [COMPO] regularly, monitoring, controlling the production... We talk to procurement... and try to have a discussion. "Sir, is there an urgent order? Which order will continue next month?" And then we discuss [things]... It (i.e. the visit) is weekly... We're open with each other... Friend becomes family... They are our family; we must help them in the field... The language is not 'stiff.'. So they won't be sungkan with us. We [feel] comfortable with each other. We use jokes...

Sungkan (reluctant) is an Indonesian cultural norm representing a feeling of disrespect or shame experienced especially if someone is unable to act as well as his or her counterpart (Geertz 1961). This is associated with a structural barrier that apparently lessened as 
familiarity evolved, encouraging more open communication through the use of informal language. The supplier explained further that this close relationship enabled him to obtain updated knowledge (exemplifying narrative knowledge) and to respond faster to urgent matters:

About the cost-reduction information - we already
knew about it [from COMPO] before the meeting
with [other] CUSTO suppliers... So we had a
picture of our customer already... If there is a
cost-down target, we can anticipate it beforehand...

Here, the supplier had a direct connection with COMPO's main customer which accelerated knowledge sharing and which was likely to enable the supplier to understand COMPO's situation better. The supplier appeared to understand COMPO's need and engaged in discussions to find the best solution. This suggests the existence of complementary behavior aimed at achieving mutual cost reduction target and an attempt to synchronizes activities with the supply chain mechanism.

With respect to non-routine tasks, knowledge exchange mainly occurred when COMPO engaged in joint activities with its network players. During joint projects, which were more complex than routine activities and involved longer-term cooperation to pursue mutual goals, knowledge exchange occurred more frequently. Each project was managed by the engineering teams from each respective company. Discussing one project with CUSTO, namely 'Projecto', COMPO's project manager remarked that before it began, CUSTO allowed COMPO time to consider the project's benefits and consequences. At the same time, COMPO also tried to understand CUSTO's situation. This reciprocity was construed by COMPO as being important in reducing project uncertainties. The project manager remarked:
I think CUSTO bas succeeded in communicating to its suppliers that the activity is good for the suppliers rather than for CUSTO itself... In the beginning, they taught us... After that, we practiced on [the] COMPO [shopfloor] directly... doing genba... They observed... The system itself is flexible... So for example, they only provided... the details about a 'lost structure'... a method to calculate. They taught us. But what we were going to do first, how to choose the model, and so on, they gave us freedom... CUSTO, I think, is more cooperative, it tries to understand us.

CUSTO did not only share specific knowledge with COMPO engineers but also allowed them to develop their own capability through practicing together, suggesting that COMPO engineers had a degree of autonomy (cf. Dowding 2006). Lessons learnt concerning the process of how and why the project goal was achieved seemed to become the prime purpose. By trusting COMPO to explore its own ways of working, CUSTO appeared to be prepared to run the risk of conflict with COMPO about how the project should be carried out. This might seem to suggest that when dealing with an uncertain or complex task, flexibility or relational governance was applied. The project manager revealed that familiarity had been established by virtue of a long-term relationship:

A personal approach could be taken, even though it's not [something we are] very aware of, because we're already familiar with CUSTO team... Here, the [project] review happens with jokes (i.e. informally). But after the meeting [we realize that], wow, during the meeting, it had all been about tasks...

Here, CUSTO seemed to try to encourage COMPO team to be more creative in finding solutions. The perceived barrier between COMPO and CUSTO was reduced as they engaged in more intense reciprocal interaction and interdependence increased, sug- 
gesting the creation of narrative knowledge. As a result, the initial stage of 'Projecto' was proclaimed by both COMPO and CUSTO to have been effective in developing a new system for increasing productivity.

\section{Knowledge exchange at internal company level}

Activities at this level (incorporating director, manager and supervisor) align with those at inter-organisational level when dealing with both routine and non-routine tasks. The improvement programme, for example, was embodied in regular activities participated in by management, alongside routine tasks arising from customer orders. All managers were required to respond to any issue quickly. One production manager explained that this concern for speed was particularly pursued through the involvement of all organisational members:

There is constructive bonding, so the speed [of improvement] becomes fast. So the activities we do, such as on Tuesday, Wednesday, Thursday, Friday, are in fact our campaign to promote the fast rolling of those [improvement] activities.

According to the production manager, communication between managers across departments mostly happened informally, and would be followed up with formal meetings. The manager explained:

The culture is to not be worried, not to be afraid of making mistakes. We (i.e. managers across departments) tend to be open if there's a problem... we discuss what we can do. Here, the relationship isn't too formal... when we have lunch, we joke with each other...

Through such open communication among managers across functions, it was expected that an integrated approach to problem-solving would developed. In light of this, a number of participants seemed to believe that the core company values promoted co- operative behavior, as remarked upon by one casting supervisor:

The core value has changed our paradigm... to promote positive values... We are trained continuously about the [company's] core values... [The result is] teamwork... [The attitude of] blaming each other is reduced... everyone wants to find a solution... They understand that blaming each other does not work anymore, it cannot solve problems.

Alongside the core values, a system was in place in the production department (exemplifying propositional knowledge), which demanded teamwork. One supervisor explained:

His activity [plan] (i.e. the manager's target) is cascaded down to me [and then to the foreman]... If the foreman fails [to accomplish this target], so do the operators... If we fail to achieve the target, we all bear this 'sin' together. We avoid this happening. So Mr. T (i.e. the production manager) always reminds us when the reject [rate] is high.

This indicates interdependence among production team members when working to accomplish work targets. The act of 'bear[ing] this sin together' suggests a sense of 'being in the same boat', signaling that bonding takes place as a result of being under pressure. At the same time, his statement that ' $M r$. T always reminds us' indicates that such togetherness was directed rather than evolving naturally. The suggestion is of a mutual perception among management that togetherness was required to achieve optimum work performance.

In brief, it appeared that a shared belief had evolved as a result of a top-down approach, which manifested itself particularly in the application of company values and the performance system. Here, trust could be contingent upon respect for the ability of 
colleagues to accomplish tasks which contributed to team performance. This production manager explained:

It doesn't mean that if my work is done, it's done. Because this is for the sake of COMPO... We have to fix it, even if it's not my job... Everyone tries to be active and contribute what we can... What we understood is how to get the work done more easily.

It appears that to gain respect (or at least acknowledgment) from colleagues, one should align one's behavior to work targets ('contribute what we can'). Other participants expressed a similar interpretation. By the same token, the manager's statement that everyone 'tries to be active' implies a tendency to regard knowledge exchange as part of effort to achieve work targets. This finding suggests that the interactions at internal company level aligned with how the supply chain was governed.

\section{Knowledge exchange at shopfloor level}

Shopfloor positions incorporated those of foreman and operator. Communication among workers mostly took place in informal ways, particularly outside working hours. They tended to communicate in vernacular (i.e. Javanese), which many saw as effective in promoting openness and togetherness, as confirmed by one operator:

On the line [we] must use formal [language], [and this] makes us awkeward or afraid of using the language wrongly. So we talk. less. But when [we're] outside the line, we're free and sometimes use Javanese... [We] enjoy using it... It is more effective...

Likewise, frequent informal activities seemed to build bonding among workers. These included getting together after work, collecting money as part of a group saving scheme, conducting arisan ${ }^{2}$ and outings. Within groups, the role of senior operator appeared to be of significance in building group culture. This was affected by the social norm of respecting senior colleagues; thus operators normally talked to their fellow senior before talking to their leader. This operator explained:

[If I find a problem] I ask the senior first, then I go to the foreman. So I don't go to the foreman directly. There's someone we respect as a senior, so if we go directly to the foreman we feel uneasy with the senior.

At the same time, a potential conflict seemed to concur with the shared norm which regarded the structural position as a hierarchical barrier as it might lead to group disharmony. In addressing this, some foremen tended to use a personal approach, such as initiating arisan to handle difficult senior operators, which was believed could nurture a family feeling among workers and reinforce teamwork. Apparently, social-cultural norms had a significant influence upon the behavior of operators; not only could they promote group solidarity, but also, if ignored, social conflict.

${ }^{2}$ Arisan (literally meaning 'mutual help') is referred to as the most common informal group activity in Indonesia, and has received extensive attention in social capital literature (Coleman 1990; Miguel et al 2003). The term relates to a fund composed of fixed contributions from each member of an association, distributed through bidding or by lot (Geertz 1962). The main purpose is to create and maintain a sense of togetherness or social harmony, although for some people the economic dimension is also important (Geertz 1962). Arisan depends on a degree of trustworthiness, as 'a person who received a payout early in the sequence of meetings could abscond, leaving the others with a loss' (Coleman 1990, p.306), which can also reinforce bonding between members. 
At shopfloor level, knowledge flow was also found in both routine and non-routine activities. With respect to how operators dealt with routine tasks, the nature of work in each production section appeared to relate to how they communicated with each other. In the casting section, for example, an operator was in charge of one or two machines, mainly using tacit skills which could be acquired by experience. Casting operators usually discussed any technical problem with more experienced colleagues. In painting section, the key process incorporated an integrated conveyor system, comprising several functions, ${ }^{3}$ each carried out by one or two operators and interrelated with other functions. If an error occurred in one function the conveyor belt was turned off, and operators working on the other functions usually investigated and helped make it operate again.

A culture of mutual assistance appeared to be in place among workers in each section. In casting, this culture seemed to evolve more naturally than in painting, possibly because casting operators tended to consider the skill of their colleagues (whether senior or junior) to be of value, particularly in helping them solve technical problems (which were more unpredictable than in the painting section). Interdependence and reciprocal exchange tended to emerge, possibly encouraging trust which not only relied upon an individual's competence but also personal friendship. In the painting section however, it seems that greater effort was needed to unite a group of operators to work as a team. Accordingly, a top-down approach was employed to ensure immediate assistance was offered by operators to a colleague in trouble.
Over time this mechanism had seemingly turned into a habit of helping each other; another foreman remarked that this had nurtured group solidarity:

The work system in painting can't be done individually... so they feel they are in the same boat'... Voluntarily [helping], that makes them strong... I think they trust each other, because if not, the conveyor can't run... If one [operator] is being rebuked [by his boss], it's impossible the others will be happy. I'm sure that they'll belp. There is a willingness to belp others.

Bonding appeared to evolve due to the fact that the approach aligned with operators' social norms which valued group harmony.

In the relationship between operators and foreman, however, an indication existed of a hierarchical barrier:

Casting operator: As operator, we see our boss, the foreman, really enjoys his work, just sitting and writing, without doing anything... Our relationship has a gap, because the level is different. Communication rarely bappens.

Painting operator: The foreman gives this [order] to achieve this [target]... He asks me to make it... I have been ordered... [and it] has to be executed, otherwise he'll get angry.

The casting operator appeared to perceive the interaction between foreman and operator to be one not of equals and which could not be said to work effectively. The painting operator remarked that the relationship conveyed a top-down approach. At the same time, some foremen said that the operators tended to pursue personal interests which could hamper productivity targets. One painting foreman indicated that such a manner needed managing:

\footnotetext{
${ }^{3}$ Painting functions are raw material loading, material treatment (i.e. washing and coating), drying, masking, blowing, electrostatic painting (using a robot), manual touching-up, baking, and cooling.
} 
Sometimes, there's someone who thinks, "If my [work] output is higher, then I won't get overtime."... Such a mindset, I have to change it gradually... by counseling, in the meeting... because if we [all] have the same mindset, I think everything will run more smoothly.

Other leaders expressed similar discouraging perceptions and had been encouraged to apply a top-down approach to manage subordinates. However, it appears that they also realized that employing a strict approach might result in an even bigger gap. Thus, some foremen were inclined to use a softer manner to gain the cooperation of operators, such as joining operators in the smoking room during breaks. This indicates that some leaders seemed to have attempted to compromise with workers' social-cultural norms in order to ensure their cooperative behavior in achieving work targets.

In dealing with non-routine activities, operators were required to submit improvement ideas as part of their individual activity plan. The purpose, according to one production manager, was to encourage a learning process. However, there was a tendency to deviate; the most obvious example was that senior operators made the individual improvement proposals to their juniors without following the required mechanism, perceiving this to be part of a culture of helping fellow juniors:

To be honest, if we have an idea, we give it to contract workers... it's reciprocity... We give the opportunity to our fellow juniors so they can be appointed [as permanent employees]... We used to ask our seniors [for ideas] [when we were still new], so this is our turn now [to give ideas] to them.

A number of foremen were aware of this conduct and were inclined to close their eyes to it; some even asked senior operators to produce improvement proposals for their juniors. This indicates a tendency to force group members to 'play the game' which at the same time, from the juniors' perspective, inhibited both knowledge exchange and learning. By engaging in this mechanism, however, not only helped workers to cope with work pressures but also to prioritize group harmony (by allowing deviant conduct and kept it to themselves).

Similarly, when workers engaged in the group improvement program, an idea might be developed if it satisfied the group interest and rejected if it was considered a threat (even if it benefited the company). On one occasion, for example, an idea was proposed which would enhance the conveyor's capacity in the painting section, which would increase work productivity and thus reduce overtime costs. However, less overtime would mean a reduction in income, and operators rejected the idea. Suppressing ideas in an effort to prioritize group conformity seemed to have a potentially inhibiting effect on knowledge exchange. This issue was discussed in the operator focus group, and one statement stands out:

Fellow workers will think, "Well, it (i.e. the idea) is only [purposed] to [enhance] his credit with the leader". So the improvement idea shouldn't be one that can be troublesome to our colleagues...

This also goes some way to confirming the existence of a structural barrier between leaders and workers. By being close with leaders, particularly by proposing an idea which went against group interest, a worker could be considered by his peers to be trying to gain credit from the boss. This behavior was considered to be in opposition to group harmony and therefore to be avoided. Thus, different with at internal company level, social interactions at this level apparently could poten- 
tially inhibit the performance of supply chain by (for instance) the operators maintaining strong reciprocity among them, ignoring the company goals.

At the same time, there was some illustrative evidence to indicate that foremen tended to apply a top-down mechanism which involved a personal approach. This apparently concurs with the company's attempt to align internal activities with the supply chain mechanism through continuous improvements, including by the application of mediation roles. It appears that by involving workers in improvement programs, knowledge exchange was able to occur among workers and between them and their leaders more intensely. Despite the misconduct that ensued, these programs have built positive connections between the shopfloor and higher levels of the hierarchy, and through these, improvements were generated.

In brief, this study evidences that strong bonding among workers promoted the possibility of conflict as a result of strict supply chain mechanism, with the potential of a detrimental effect on the connections between levels. Here, the role of mediators played a significant part in reducing the negative effects of a) the company's tight control and b) the collective action of the workers, and helping the company to better align its activities with the supply chain dynamics by sustaining knowledge flow across levels.

\section{Discussion}

Derived from the case study, task-focused knowledge exchange in COMPO dealt with both routine and non-routine activities. The routine activities were more dominantly governed by formal contracts (propositional knowledge), ensuring that all the activities aligned with the supply chain mechanism. Whereas the non-routine activities in the form of joint projects allowed the companies to apply more relational governance. Some authors such as Gulati and Gargiulo (1999) have argued that relational governance is able to promote a socially structured mechanism. The present research finding enhances this argument that such a mechanism did exist between people at different levels and boundaries in the supply chain through non-routine tasks where informal norms established.

At inter-organizational level, knowledge exchange was facilitated by applying mediation roles, between COMPO and its buyers and suppliers. The mediators played a critical role in aligning functional activities with the supply chain mechanism, not only by connecting different parties structurally, but also by activating relational bonding through reciprocal interactions. Here the mediators were able to moderate the strictly-governed supply chain, through which knowledge could flow across different levels. This finding contributes to the existing literature (e.g. Krause et al. 2007, Aggarwal et al. 2011, Whipple et al. 2015) that the strict governance at inter-organizational level can be moderated by social interactions through the mediator role (e.g. marketing, purchasing, engineer positions), whether stickiness or leakiness may decrease as a result. The mediator role was more evident during non-routine tasks suggest that COMPO was able to accelerate improvements (creating narrative knowledge) by helping create trust and mutual understanding with its customers and suppliers. During 'Projecto' for example, engineers from both companies were directly connected and engaged in simultaneous interactions in order to develop the project. This connection appeared to promote trust through the generation of improvements. 
At internal company level, the indication is that management engaged in extensive interaction with both external and internal parties. The structural configuration at this level appeared to benefit managers in that they acquired knowledge easily where spontaneous knowledge exchange and immediate decision-making were facilitated. This seems to concur with the need for fast knowledge flow to keep production activities aligned with supply chain dynamics, where the company values ingrained in managers' behavior. In dealing with more complex assignments it appears that a connection was created which helped promote shared understanding between managers regarding how projects could support productivity goals. This enhances the earlier argument in that managers as mediators helped facilitate mutual understanding in complex assignments where a constant state of change existed. In this regard, the managers engaged in a shared preferred outcome and shared a cause/effect belief concerning the importance of teamwork in achieving goals (cf. Thompson 1967) through intensive social interaction with both internal and external people. The company core values and supporting systems apparently could help encourage the interactions in their daily activities.

At shopfloor level, the finding suggests that the work mechanism in each section had an impact upon how workers exchanged knowledge. In casting section, for instance, knowledge exchange occurred more naturally as the operators were challenged to solve more complex technical problems. In painting, knowledge exchange occurred as part of the way the culture of teamwork was institutionalized to deal with troubleshooting. Apparently, by being engaged in such continuing interaction, a shared belief in prioritizing group conformity had emerged among paint- ing operators. In both sections, propositional knowledge was supplemented by narrative knowledge along with the intensification of interaction among workers (exemplifying the concept of Tsoukas 2005). However, such bonding had the potential to have an adverse impact on knowledge exchange in generating improvement ideas, for example when workers made an agreement to manipulate improvement proposals. This suggests that formal governance (propositional knowledge) being applied at the inter-organizational level could promote social interaction among workers (narrative knowledge) that potentially inhibit knowledge flow across levels. In this regard, the role of mediators was of importance in reducing the negative effects and ensuring the company to better align its activities with the supply chain dynamics by sustaining knowledge flow across levels. The finding potentially extends the understanding of existing research (e.g. Cooper et al 1997; Mentzer et al 2001): the top-down approach on the part of buyers could be moderated by the internal differentiation across levels of interaction. Here, the role of foremen as mediators played a significant part in reducing the negative effects of the strict supply chain mechanism and the collective action of operators, and helping the company to better align its activities with the supply chain dynamics by sustaining knowledge flow across levels.

The present study also contributes to the understanding of how formal governance and relational governance complement each other, as coined by Carey and Lawson (2001) as well as Poppo and Zenger (2002). The finding extends this that the complementary effect had promoted interdependence between COMPO and its suppliers and buyers where knowledge exchange was facilitated. At the same time, the interdependency at in- 
ter-organizational level could encourage an adverse effect at shopfloor level (as the result of top-down approach), which then inhibited knowledge flow between levels, such as in the form of manipulation by the workers (suggesting group conformity). In this regard, the negative effect of formal governance was able to be moderated by the role of mediators (applying a relational approach). In brief, this suggests that the activation and development of relational connections across levels, either structurally or mechanistically (e.g. the improvement programs and the institutionalized company culture) or more spontaneously (e.g. social norms between workers), could either promote or inhibit the flow of knowledge across levels of interaction.

\section{Conclusion}

The present case study answers the research question of how knowledge exchange occurs in a hierarchical mechanism context: knowledge exchange is not simply influenced by governance arrangements but also by the activation and development of relational connections across levels, either structurally or more spontaneously. The finding contributes to the theories of knowledge exchange in a multiple-level of analysis, which has hitherto been rarely discussed. The existing literature, for instance, states that supply chain governance plays a significant role to manage knowledge flow at inter-organizational level (e.g. Nooteboom 2000, Krause et al. 2007, Aggarwal et al. 2011, Whipple et al. 2015), but the literature does not explain how knowledge stickiness and leakiness can be moderated by internal differentiation across levels of interaction. The present research indicates that the problems of knowledge stickiness and leakiness which occurred as a conse- quence of governance structures established at inter-organizational level could be moderated by internal differentiation across levels of interaction where stickiness or leakiness may be as a result heightened or lessened along with the development of connections between actors.

The present study indicates connection building across levels that relied upon relational approaches to promote knowledge flow, as well as knowledge creation in some occasions. This corresponds with COMPO's attempt to align activities at every level with the supply chain mechanism (cf. Turnbull et al. 1992, Mentzer et al. 2001, Barratt 2004). Approaches both organic and mechanistic emerged, both of which were able to facilitate knowledge exchange. With respect to the mechanistic (structural) approach, it appears that some connections emerged and helped members of the organization synchronize their conduct with the required mechanism. This promoted shared understanding of how a strictly-controlled mechanism could promote knowledge flow across levels, relying upon the development of relational connections between actors across levels. In this regard, the role of mediator was of importance in building a shared perception about work targets among the organizational members by combining tight control with softer approaches.

The present study also indicates that interaction (in both formal and informal setting) at one level of analysis can impact on interaction at other levels. Interactions among workers on the shopfloor that tended to constrain knowledge flow, for instance, had encouraged the mediators (such as foremen and managers) to activate relational bonding through reciprocal interactions between people at inter-organizational level and 
shopfloor level. In this way, knowledge exchange across levels could be facilitated. Here, where social interactions that exist at one level of analysis influence interactions at other levels, the mediators play their part to actively bridge the company and the workers by considering social-cultural norms. This suggests the significance of mediation roles to sustain the recursive relationship to promote knowledge exchange across levels.

The substantive issues addressed in this research suggest several directions for further enquiry. The examination of knowledge, for example, is focused on the process of ex- change in the production process of manufacturing company. Future research could extend this work by examining knowledge generation as the outcomes of knowledge exchange in order to understand how a particular process of exchange influences knowledge generation, and how it influences company performance in other sectors. Further study can also be done to gain the precise understanding of how different configurations of governance mechanism in other sectors (such as the service industry) might influence flows of knowledge within and between supply chain partners.

\section{Acknowledgment}

The author gratefully acknowledge helpful supervision from Professor Mike Bresnen as Main Supervisor and Dr. Yanuar Nugroho as Co-Supervisor in developing the idea of this paper, as part of the author's doctoral study.

\section{References}

Aggarwal, V. A., N. Siggelkow, and H. Singh. 2011. Governing collaborative activity: interdependence and the impact of coordination and exploration. Strategic Management Journal 32: 705-730.

Ambrosini, V., and C. Bowman. 2001. Tacit knowledge: some suggestions for operationalization. Journal of Management Studies 38: 811-829.

Baker, W. E. 1990. Market networks and corporate behavior. American Journal of Sociology 98: 589-625.

Barratt, M. 2004. Understanding the meaning of collaboration in the supply chain. Supply Chain Management 9: 30-43.

Bradach, J. L., and R. G. Eccles. 1989. Price, authority, and trust: from ideal types to plural forms. Annual Review of Sociology 15: 97-118.

Bresnen, M. 1996. An Organizational perspective on changing Buyer-Supplier relations: A critical review of the evidence. Organization 3: 121-146.

Brown, J. S., and P. Duguid. 1991. Organizational learning and communities-of-practice: Toward a unified view of working, learning, and innovation. Organization Science 2: 40-57.

Brown, J. S., and P. Duguid. 2001. Knowledge and organization: A social-practice perspective. Organization Science 12: 198-213.

Bryman, A. 2008. Social Research Method. New York, Oxford University Press. 
Carey, S., and B. Lawson. 2011. Governance and social capital formation in buyer supplier relationships. Journal of Manufacturing Technology Management 22: 152-170.

Child, J. 1972. Organizational structure, environment and performance: The role of strategic choice. Sociology 6: 1-22.

Coleman, J. S. 1988. Social capital in the creation of human capital. American Journal of Sociology 94: S95S120.

Cook, S. D. N., and J. S. Brown. 1999. Bridging epistemologies: The generative dance between organizational knowledge and organizational knowing. Organization Science 10: 381-400.

Cooper, M. C., D. M. Lambert, and J. D. Pagh. 1997. Supply chain management: More than a name for logistics. The International Journal of Logistics Management 8: 1-14.

Corbin, J., and A. Strauss. 1990. Grounded theory research: Procedures, canons, and evaluative criteria. Zeitschrift fur Soziologie 19: 418-427.

Creswell, J. W. 2007. Qualitative Inquiry and Research Design - Choosing Among Five Approaches. California: SAGE Publications.

Dowding, K. 2006. Three-dimensional power: A discussion of Steven Lukes' Power: A radical view. Policy Studies Review 4: 136-145.

Dyer, J. H. 1996. Specialized supplier networks as a source of competitive advantage: evidence from the auto industry. Strategic Management Journal 17: 271-291.

Ebers, M. 1997. Explaining Inter-Orgnizational Network Formation. In Ebers, M. (Ed.). The Formation of Inter-Organizational Networks. New York: Oxford University Press.

Geertz, H. 1961. The Javanese Family. A Study of Kinship and Socialization. New York: The Free Press.

Gill, J., and P. Johnson. 2006. Research Methods for Managers. London: SAGE Publications Ltd.

Gulati, R., and M. Gargiulo. 1999. Where do interorganizational networks come from. American Journal of Sociology 104: 1439-1493.

Gulati, R., N. Nohria, and A. Zaheer. 2000. Strategic networks. Strategic Management Journal 21: 203-215.

Gulati, R., and H. Singh. 1998. The architecture of cooperation: Managing coordination costs and appropriation concerns in strategic alliances. Administrative Science Quarterly 43: 781-814.

Hippel, E. V. 1994. Sticky information and the locus of problem solving: Implications for innovation. Management Science 40: 429-439.

Inkpen, A. C., and E. W. K. Tsang. 2005. Social capital, networks, and knowledge transfer. Academy of Management Review 30: 146-165.

Isabella, L. A. 1990. Evolving interpretations as a change unfolds: How managers construe key organizational events. Academy of Management Journal 33: 7-41.

Ketchen, D. J., and G. T. M. Hult. 2007. Bridging organization theory and supply chain management: The case of best value supply chains. Journal of Operations Management 25: 573-580.

Kogut, B. 2000. The network as knowledge: generative rules and the emergence of structure. Strategic Management Journal 21: 405-425.

Krause, D. R., R. B. Handfield, and B. B. Tyler. 2007. The relationships between supplier development, commitment, social capital accumulation and performance improvement. Journal of Operations Management 25: 528-545. 
Lambert, D. M., M. C. Cooper, and J. D. Pagh. 1998. Supply chain management: implementation issues and research opportunities. International Journal of Logistics Management 9: 1-19.

Larson, A. 1992. Network dyads in entrepreneurial settings: A study of the governance of exchange relationships. Administrative Science Quarterly 37: 76-104.

Macneil, I. R. 1985. Relational contract: what we do and do not know. Wisconsin Law Review: 483-525.

Martin, J. A., and K. M. Eisenhardt. 2010. Rewiring: cross-business-unit collaborations in multibusiness organizations. Academy of Management Journal 53: 265-301.

Mason, J. 2002. Qualitative Researching. London: SAGE Publications.

Mentzer, J. T., W. Dewitt, J. S. Keebler, S. Min, N. W. Nix, C. D. Smith, and Z. G. Zacharia. 2001. Defining supply chain management. Journal of Business Logistics 22: 1-25.

Miles, M. B., and A. M. Huberman. 1994. An Expanded Sourcebook, Qualitative Data Analysis. California: SAGE Publications.

Nooteboom, B. 2000. Learning by interaction: Absorptive capacity, cognitive distance, and governance. Journal of Management and Governance 4: 69-92.

Orlikowski, W. J. 2002. Knowing in practice: Enacting a collective capability in distributed organizing. Organization Science 13: 249-273.

Polanyi, M. 1958. Personal Knowledge, Towards a Post-Critical Philosophy. Chicago: The University of Chicago Press.

Poppo, L., and T. Zenger. 2002. Do formal contracts and relational governance function as substitutes or complements? Strategic Management Journal 23: 707-725.

Provan, K. G., and J. B. Gassenheimer. 1994. Supplier commitment in relational contract exchanges with buyers: A study of interorganizational dependence and exercised power. Journal of Management Studies 31: 55-68.

Ring, P. S., and A. H. V. D. Ven. 1992. Structuring relationships between organizations. Strategic Management Journal 13: 483-498.

Smitka, M. J. 1991. Competitive Ties, Subcontracting in the Japanese Automotive Industry. New York: Columbia University Press.

Squire, B., P. D. Cousins, and S. Brown. 2009. Cooperation and knowledge transfer within buyer-supplier relationships: The moderating properties of trust, relationship duration and supplier performance. British Journal of Management 20: 461-477.

Szulanski, G. 1996. Exploring internal stickiness: Impediments to the transfer of best practice within the firm. Strategic Management Journal 17: 27-43.

Takeishi, A. 2001. Bridging inter- and intra-firm boundaries: Management of supplier involvement in automobile product development. Strategic Journal Management 22: 403-433.

Teece, D. J., R. Rumelt, G. Dosi, and S. Winter. 1994. Understanding corporate coherence. Theory and evidence. Journal of Economic Behavior and Organization 23: 1-30.

Thompson, J. D. 1967. Organizations in Action. New York: Mc Graw-Hill.

Tsoukas, H. 2005. Complex Knowledge, Studies in Organizational Epistemology. Oxford: Oxford University Press.

Tsoukas, H., and E. Vladimirou. 2001. What is organizational knowledge? Journal of Management Studies 38: 973-994. 
Turnbull, P., N. Oliver, and B. Wilkinson. 1992. Buyer-supplier relations in the UK automotive industry: Strategic implications of the Japanese manufacturing model. Strategic Management Journal 13: 159168.

Uzzi, B. 1997. Social structure and competition in interfirm networks: the paradox of embeddedness. Administrative Science Quarterly 42: 35-67.

Whipple, J. M., R. Wiedmer, and K. K. Boyer. 2015. A dyadic investigation of collaborative competence, social capital, and performance in buyer supplier relationships. Journal of Supply Chain Management 51: $1-38$.

Williamson, O. E. 1985. The Economic Institutions of Capitalism: Firms, Markets, Relational Contracting. New York: The Free Press. 


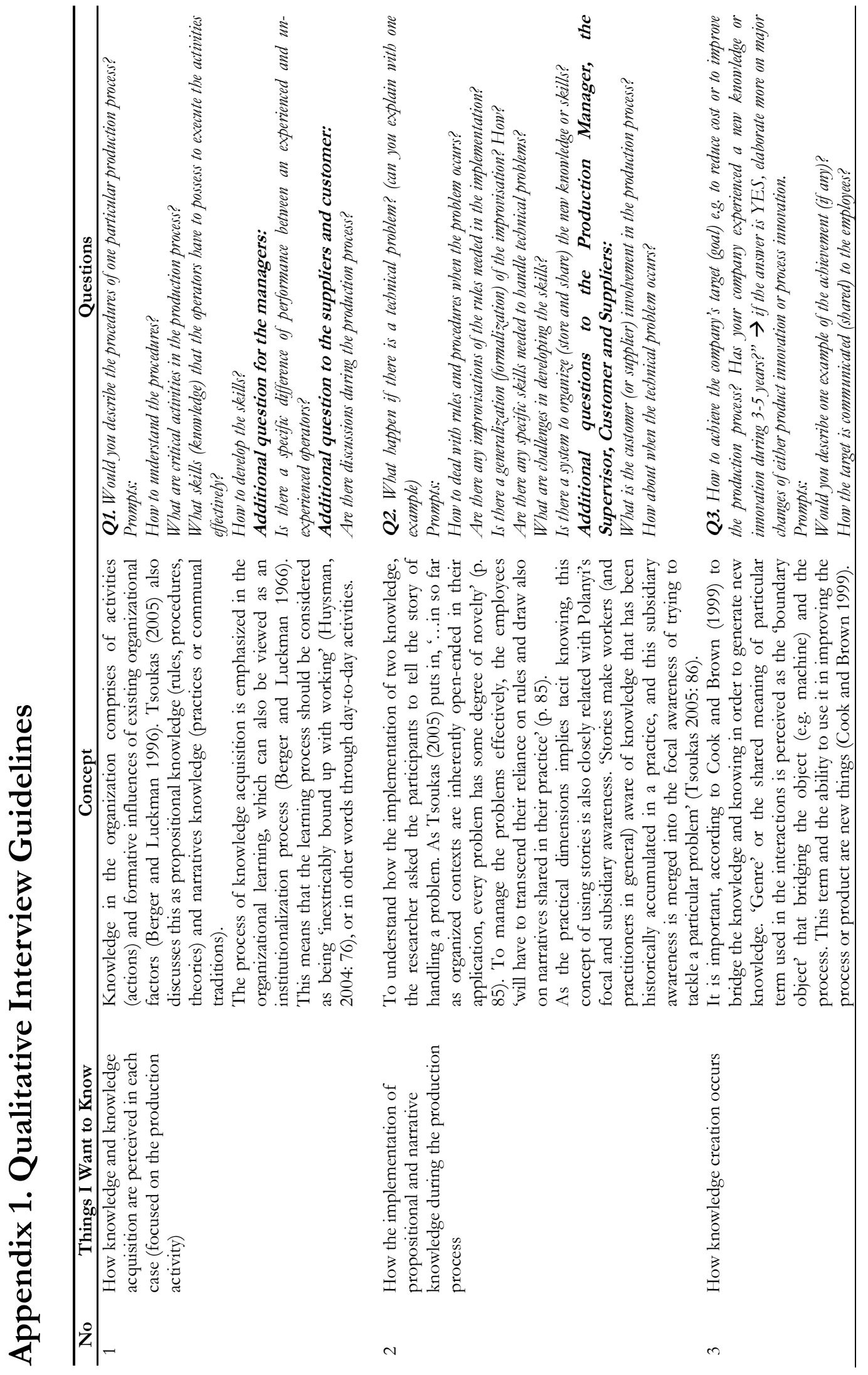

